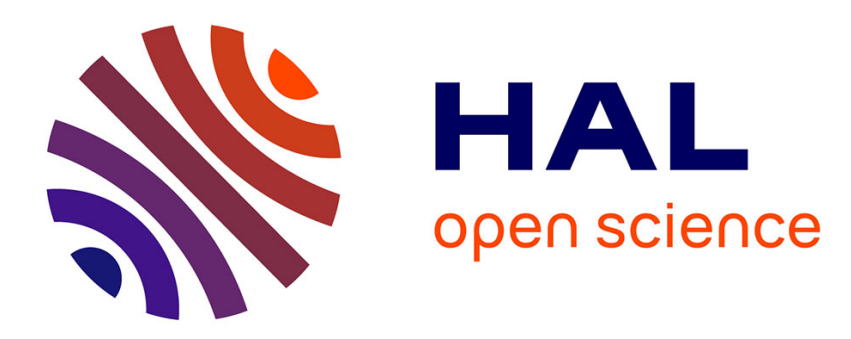

\title{
ELLIPSOMETRIC STUDIES OF OXYGEN ADSORBED ON SILVER FILMS
}

\author{
M. Watanabe, P. Wissmann
}

\section{To cite this version:}

M. Watanabe, P. Wissmann. ELLIPSOMETRIC STUDIES OF OXYGEN ADSORBED

ON SILVER FILMS. Journal de Physique Colloques, 1983, 44 (C10), pp.C10-459-C10-462. 10.1051/jphyscol:19831090 . jpa-00223548

\section{HAL Id: jpa-00223548 https://hal.science/jpa-00223548}

Submitted on 1 Jan 1983

HAL is a multi-disciplinary open access archive for the deposit and dissemination of scientific research documents, whether they are published or not. The documents may come from teaching and research institutions in France or abroad, or from public or private research centers.
L'archive ouverte pluridisciplinaire HAL, est destinée au dépôt et à la diffusion de documents scientifiques de niveau recherche, publiés ou non, émanant des établissements d'enseignement et de recherche français ou étrangers, des laboratoires publics ou privés. 


\author{
M. Watanabe and P. Wissmann* \\ Reseanch Institute for Catalysis, Hokkaido University, Sapporo, 060 Japan \\ * Institut fur Physikalische und Theoretische Chemie der Universitat \\ Eriangen-Nurnberg, Egeriandstrasse 3, 8520 Eriangen, F.R.G.
}

\begin{abstract}
Résumé - L'adsorption d'oxygène sur des couches minces d'Argent déposées par êvaporation a été étudiée à 295 et $77 \mathrm{~K}$ par ellipsométrie et par mesures de résistance. La constante diélectrique obtenue pour l'oxygène adsorbé sous forme atomique, à $1152 \mathrm{~nm}$, est $\tilde{\varepsilon}_{1}=-1,8-3,5 \mathrm{i}$ à $295 \mathrm{~K}$ et $-2,0-4,0 \mathrm{i}$ à $77 \mathrm{~K}$; ces valeurs sont bien interprétées par $1 \mathrm{la}$ théorie de Bennett et Penn qui décrit le couplage entre l'oxygène adsorbé et les électrons de conduction. Les valeurs $\delta \Delta$ et $\delta \psi$ observées à $\lambda=633 \mathrm{~nm}$ indiquent l'existence d'une couche d'interface induite. La constante diélectrique de 1 'oxygène adsorbé sous forme moléculaire à $77 \mathrm{~K}$ est réelle et égale à $\varepsilon_{1}=1,8$.

Abstract - Adsorption of oxygen on evaporated silver films is studied at 295 and $77 \mathrm{~K}$ by means of ellipsometry and resistance measurements. The dielectric constant of atomically adsorbed oxygen obtained at $\lambda=1152 \mathrm{~nm}$ is $\tilde{\varepsilon}_{1}=$ $-1.8-3.5 i$ at $295 \mathrm{~K}$ and $-2.0-4.0 i$ at $77 \mathrm{~K}$, which are well understood by the Bennett and Penn theory describing coupling between adsorbed oxygen and conduction electrons. Observed $\delta \Delta$ and $\delta \psi$ values at $\lambda=633 \mathrm{~nm}$ indicate the existence of an induced interface layer. The dielectric constant of molecularly adsorbed oxygen at $77 \mathrm{~K}$ is found to be real as $\varepsilon_{1}=1.8$.
\end{abstract}

Oxygen is atomically adsorbed on polycrystalline silver surfaces at room temperature while at $77 \mathrm{~K}$ it seems to be adsorbed atomically at early stage of adsorption and then weakly and molecularly |1-3|. We intend in this paper to compare ellipsometric response of adsorbed oxygen at $295 \mathrm{~K}$ with that at $77 \mathrm{~K}$. A few other groups have studied this system at room temperature by means of ellipsometry using light wavelengths of $633 \mathrm{~nm}$ or shorter $|4-6|$. Our light source was a He-Ne laser of $\lambda=1152 \mathrm{~nm}$, where the metal dielectric constant can be described by an extended Drude equation including the anomalous skin effect. As well we used another He-Ne laser of $633 \mathrm{~nm}$ to compare our results with literature work. Evaporated thin films were considered to be advantageous for determining the life time of conduction electrons and Fuch's specularity parameter from resistivity measurements. We measured changes in the ellipsometric angles $\delta \Delta$ and $\delta \psi$ as a function of oxygen coverage, which were converted into the complex dielectric constants of adsorbed oxygen. They were found to be different from those of 1 iquid or gas phase oxygen.

\title{
I - EXPERIMENTS
}

Experimental details are given elsewhere |7,8|. A null method ellipsometer (Rudolph 43603-200E) was used in the PSCA arrangement. Samples were polycrystalline and continuous films deposited on glass substrates in UHV conditions. Spectrally pure silver was evaporated from a tungsten helix heater onto the substrate which was kept at ambient temperature. The thickness $D$ of the films was in the range of 25 to $50 \mathrm{~nm}$, which was determined by atom absorption spectroscopy. The resistance of the films was measured by a so-called four electrode method during evaporation, annealing and gas admissions. The gas dose was provided by breaking the seals of ampoules filled with $\mathrm{O}_{2}$ gas of $99.999 \%$ purity. The adsorbed amount of $\mathrm{O}_{2}$ was determined by monitoring increments of the resistance using calibration curves obtained for spherical glass cells $|8|$. Since variations in $\Delta$ and $\psi$ due to $0_{2}$ adsorption were small, we evaluated them with the help of computer analysis. Details of the method are given elsewhere $|9|$. 


\section{II - RESULTS}

Electron micrographs show that a continuous film structure with a preferred (111) orientation is formed for $D \geq 15 \mathrm{~nm}$. The films become smoother with increasing $D$. Observed $\Delta$ and $\psi$ values of the films without adsorbate are converted into dielectric constant $\tilde{\varepsilon}_{2}$ by computer calculations of a two layer system including the metal films and the glass substrate with refractive index of 1.48. 0btained dielectric constant is $\tilde{\varepsilon}_{2}=(-75 \pm 4)-(2.5 \pm 0.5)$ i at $\lambda=1152 \mathrm{~nm}$ while the Drude equation gives $\tilde{\varepsilon}_{2}=$ $-72.5-2.34 i$ with $\varepsilon_{b}=2.5$ being the core electrons contribution $|10|$. At $\lambda=633 \mathrm{~nm}$ we obtained $\tilde{\varepsilon}_{2}=(-22 \pm 2)-(0.4 \pm 0.2)$ i while the Drude value is $\tilde{\varepsilon}_{2}=-19.5-0.48 i$. Thus the observed $\tilde{\varepsilon}_{2}$ values are we $17^{*}$ described by the Drude theory.

Solid curves in Fig. la show the coverage dependence of the ellipsometrical parameters $\delta \Delta$ and $\delta \psi$ defined as

$$
\delta \Delta=\Delta(\theta=0)-\Delta(\theta), \quad \delta \psi=\psi(\theta=0)-\psi(\theta),
$$

where $\theta$ is the degree of oxygen coverage. It was ascertained that $\delta \Delta$ and $\delta \psi$ are independent of $\mathrm{film}$ thickness $\mathrm{D}$ when it is larger than $25 \mathrm{~nm}$. If an adlayer is transparent for an incident light, a simple stratified layer model predicts $|11|$ :

$$
\delta \Delta=C(\lambda) \alpha \theta / \lambda \quad \delta \psi \leq 0,
$$

where $\alpha$ is the atomic polarizability of the adsorbate and $C(\lambda)$ is a function of $\lambda$, incident angle of the light and adsorbent optical properties. Obviously the results of Fig. 1a are very inconsistent with eq. (2), so that we may need an induced interface layer and/or a complex dielectric constant of adsorbed oxygen to explain the data. The $6.4 \%$ increase in the resistance seems to indicate that oxygen atoms are not adsorbed by silver for $0_{2}$ pressures smaller than $1.3 \mathrm{~Pa}$ used in the present experiments (see Fig. 1b).

At $77 \mathrm{~K}$ observed changes in $\delta \Delta$ and $\delta \psi$ values are $\delta \Delta=0.28^{\circ}, \delta \psi=0.07^{\circ}$ at $\lambda=$ $1152 \mathrm{~nm}$ and $\delta \Delta=1.0^{\circ}, \delta \psi=-0.22^{\circ}$ at $633 \mathrm{~nm}$ for the coverage of $\mathrm{Nad}=4.0 \times 10^{14} \mathrm{~mole}-$ cules $/ \mathrm{cm}^{2}$. At low coverages, variations in $\delta \Delta, \delta \psi$ and $\delta R$ are similar to those in Fig. 1 though $\delta \psi$ at $633 \mathrm{~nm}$ is largely negative. At high coverages $\delta \Delta$ is almost linear and $\delta \psi$ is constant. A Characteristic feature is that $\delta \Delta$ does not tend to saturate at high coverages unlike that at $295 \mathrm{~K}$, possibly due to weak adsorption of molecular oxygen. The maximum change in the resistance $\delta R / R$ at $77 \mathrm{~K}$ is 7.2 . \% for a $\mathrm{Ag}$ film of $D=42 \mathrm{~nm}$.

\section{DISCUSSION}

The surfaces of the evaporated Ag films are treated to be flat, which is an admissible assumption because their bumpiness is much smaller than $\lambda$. Furthermore, we now take into account that the glass substrate only influences the absolute values of $\Delta$ and $\psi$ but is ineffective for $\delta \Delta$ and $\delta \psi$ when the thickness of $\mathrm{Ag}$ films is larger than the skin depth $\delta_{s}=21 \mathrm{~nm}$. Applying the model of Fig. $2 b, \delta \Delta$ and $\delta \psi$ are expressed in simply analytical forms by the linear approximation under the condition of $d_{a d} / \lambda \ll 1$. Non-classical expressions of $\delta \Delta$ and $\delta \psi$ which include the non-local effects were given in a previous paper $|10|$ :

Fig. I Changes in ellipsometric angles $8 \Delta, 8 \psi$ at $1152 \mathrm{~nm}(0, \Delta)$ and $633 \mathrm{~nm}(\bullet, \Delta)$ and resistance of Ag film $8 \mathrm{R}$ plotted with the coverage of adsorbed oxygen of $295 \mathrm{~K}$. Dotted curve shows calculated $8 \psi$ which arises from the parameter effect. Simulations of $8 \Delta$ and $8 \psi$ at $1152 \mathrm{~nm}$ are given by chained curves.
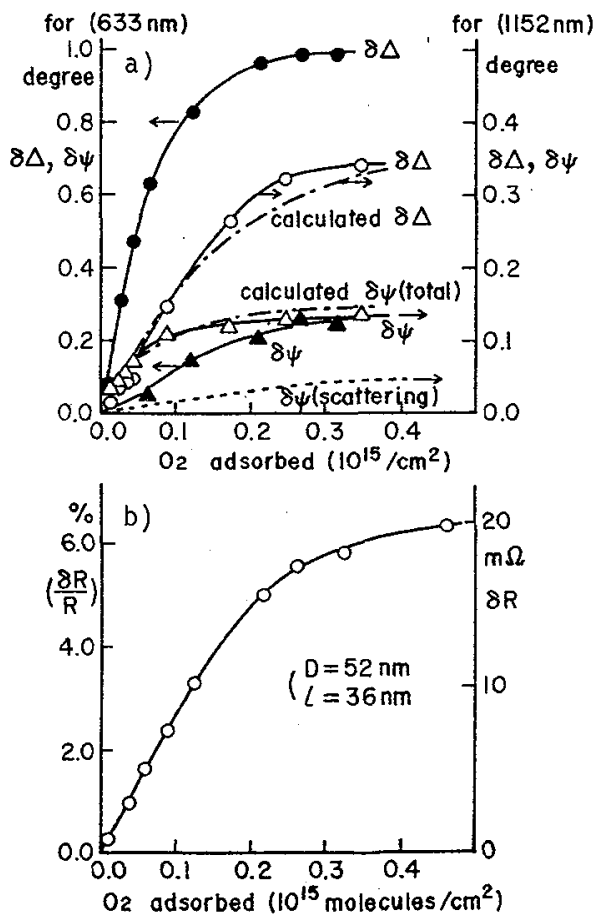


$$
\begin{aligned}
& \delta \Delta=\frac{-4 \pi d_{a d}{ }_{0} \cos \phi_{0}}{\lambda} \times \operatorname{Re}|F n| \\
& \delta \psi=\sin 2 \psi \frac{2 \pi d_{a d_{0} n_{0} \cos \phi_{0}}^{\lambda} \times \operatorname{Im}|F n|}{\lambda} \\
& F n=\left(\frac{\tilde{\varepsilon}_{1}-\tilde{\varepsilon}_{2}}{\tilde{\varepsilon}_{0}-\tilde{\varepsilon}_{2}}\right)\left\{\frac{1-\varepsilon_{0}\left(1 / \tilde{\varepsilon}_{1}+1 / \tilde{\varepsilon}_{2}\right) \sin ^{2} \phi_{0}+\tilde{\varepsilon}_{1} Q /\left(\tilde{\varepsilon}_{1}-\tilde{\varepsilon}_{2}\right)}{1-\varepsilon_{0}\left(1 / \varepsilon_{0}+1 / \tilde{\varepsilon}_{2}\right) \sin ^{2} \phi_{0}+\varepsilon_{0} Q /\left(\varepsilon_{0}-\tilde{\varepsilon}_{2}\right)}-1\right\} \\
& Q=2 \gamma\left(\tilde{\varepsilon}_{2}-\varepsilon_{0} \sin ^{2} \phi_{0}\right)^{1 / 2}+\tilde{\varepsilon}_{2} \gamma^{2}, \quad \gamma=\frac{1}{\left(K_{l}\right)_{n}}\left(\frac{\varepsilon_{0}}{\tilde{\varepsilon}_{2}}-\frac{\varepsilon_{0}}{\tilde{\varepsilon}_{1}}\right) \sin ^{2} \phi_{0}
\end{aligned}
$$

where definitions of variables and dielectric constants are given in Fig. 2. $\left(K_{\ell}\right)_{n}$ is the normal component of iongitudinal wave vector $|12,13|$. When $\gamma$ is smal1, then $\delta \Delta$ and $\delta \psi$ reduce to the classical forms. Eqs. 3 are the expressions at $\theta=1$. Since the observed $\delta \Delta$ and $\delta \psi$ values are non-linear with coverage, the coverage curves are analyzed with the help of Lorentz-Lorenz equation by substituting $\tilde{\varepsilon}_{1}$ in eqs. 4 and 5 by $\tilde{\varepsilon}_{1}(\theta)$ according to $|10|$

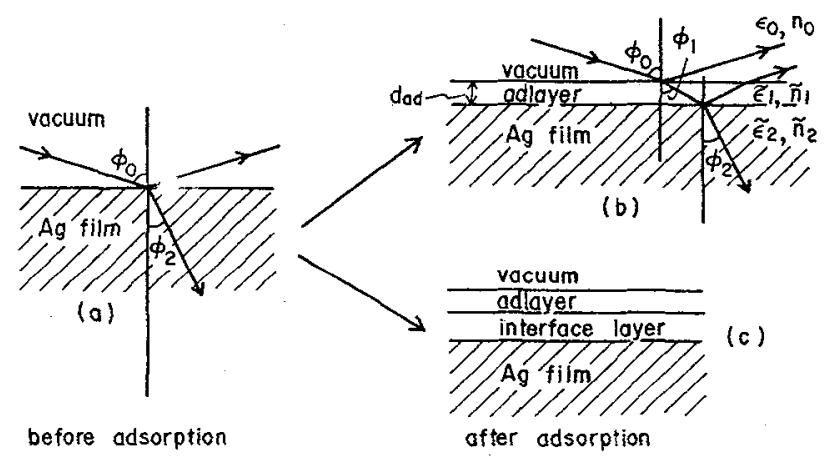

Fig. 2 Strotified layer model of oxygen adsorption on Ag films and definitions of voriables.

$$
\frac{\tilde{\varepsilon}_{1}(\theta)-1}{\tilde{\varepsilon}_{1}(\theta)+2}=\theta\left(\frac{\tilde{\varepsilon}_{1}-1}{\tilde{\varepsilon}_{2}+2}\right)
$$

The dielectric constant of $\mathrm{Ag}$ is given by the extended Drude equation including anomalous skin effects $|10,14|$ as

$$
\tilde{\varepsilon}_{2}=\left\{1-\left(\frac{\omega_{p}}{\omega}\right)^{2}\right\}-i\left(\frac{\omega_{p}}{\omega}\right)^{2} \cdot \frac{1}{\omega \tau}\left\{1+\frac{3}{8}(1-p)\left(\frac{\ell_{o p}}{\delta_{s}}\right)\left(1-\left(\frac{\omega}{\omega_{p}}\right)^{2}\right)^{3 / 2}\right\},
$$

with

$$
1 / \tau_{\text {op }}=1 / \tau_{\text {st }}+1 / \tau_{\text {ee }},
$$

where $\omega$ and $\omega_{p}$ are frequencies of incident light and the plasmon, respectively, $\delta_{S}$ is the skin depth, $p$ is the Fuchs specularity parameter, $\tau_{o p}=v / 1_{o p}$ is the optical life time of conduction electrons, $\tau_{s t}$ is the static life time calculated from observed resistance of $\mathrm{Ag}$ films and $\tau_{\mathrm{ee}}$ is the life time determined from electronelectron collisions |15| which are important when $\omega$ is large and the Fermi surface is non-spherical or surface scatterings of conduction electrons are effective.

Since the films are assumed to be flat, the resistance is analyzed by the FuchsSondheimer theory. Observed resistance changes are approximately expressed by $|10|$ :

$$
\left(\frac{\delta R}{R}\right)=\left(\frac{\delta \rho}{\rho}\right) \simeq \frac{\delta p}{2\left(\frac{8}{3} \frac{D}{T}-1\right)}
$$


from which we calculated $\delta p$ by using observed $(\delta R / R)$ values. $D / 1$ is 1.4 at $295 \mathrm{k}$, thus we obtain $\delta p=0.36$. After numerical calculations we found that this leads to $\delta \psi=0.05^{\circ}$, which is illustrated by the dotted curve in Fig. I. The calculation reveals that $\delta p$ influences only little $\delta \Delta$. For the $77 \mathrm{~K}$ results, similar conclusions hold.

Following the above procedure we simulated observed $\delta \Delta$ and $\delta \psi$ curves with parametrizing $\tilde{\varepsilon}_{1}$ and $d_{a d}$, but $d_{a d}$ is fixed around $0.2 \mathrm{~nm}$ for atomic oxygen and around $0.35 \mathrm{~nm}$ for molecular oxygen. At $295 \mathrm{~K}$ adsorbed oxygen is atomic. Simulation curves of $\delta \Delta$ and $\delta \psi$ are shown in Fig. 1 at $1152 \mathrm{~nm}$ with best fitted $\tilde{\varepsilon}_{1}$ value being $\tilde{\varepsilon}_{1}=-1.8-3.5 i$. On the other hand, at $633 \mathrm{~nm}$ none of $\tilde{\varepsilon}_{1}$ values can interpret the coverage curves, in particular with respect to the steep rise of $\delta \Delta$ at the early coverage. Therefore, we conclude that at $633 \mathrm{~nm}$ the formation of an induced interface layer must be taken into account, i.e. model (c) rather than model (b) should be applied. This conclusion implies that dielectric constant of the interface Tayer depends strongly on $\lambda$ Tike $\tilde{\varepsilon}_{2}$ of Ag. In model (c), determination of $\tilde{\varepsilon}_{1}$ is impossible because of many unknown parameters.

Along the same lines we analyzed our low coverage data at $77 \mathrm{~K}$. We simulated coverage curves of $\delta \Delta$ and $\delta \psi$ and arrived at the same conclusion that model (b) explains well the result at $1152 \mathrm{~nm}$ with simulation parameters of $\tilde{\varepsilon}_{1}=-2.0-4.0 i$ and $d_{a d}=0.2 \mathrm{~nm}$, but does not explain at all the result at $633 \mathrm{~nm}$, white model (c) does. Observed changes in ellipsometric angles in the high coverage range are $\delta \Delta=0.15^{\circ}, \delta \psi=-0.020$ at $1152 \mathrm{~nm}$ and $\delta \Delta=0.40^{\circ}, \delta \psi=0.00^{\circ}$ at $633 \mathrm{~nm}$, which can be interpreted by weak $7 \mathrm{y}$ adsorbed molecular oxygen with $\tilde{\varepsilon}_{1}=1.8-0.0 \mathrm{i}$ and $\mathrm{d}_{\mathrm{ad}}=0.35 \mathrm{~nm}$.

\section{CONCLUSIONS}

Dielectric constants of atomic oxygen on silver at $1152 \mathrm{~nm}$ are $\tilde{\varepsilon}_{1}=-1.8-3.5 i$ at $295 \mathrm{~K}$ and $\tilde{\varepsilon}_{1}=-2.0-4.0 \mathrm{i}$ at $77 \mathrm{~K}$. Such complex dielectric constants with negative real parts were predicted by the Bennett and Penn theory $|16|$ describing possible resonant bonds between adsorbates and conduction electrons. UPS spectra of adsorbed oxygen on silver $|3,17|$ show two peaks at 8.0 and $12 \mathrm{eV}$ from $E_{f}$ which 7 ie below the conduction band, and a peak at $3.2 \mathrm{eV}$ in the sp conduction band. Dielectric properties of adsorbed oxygen may reflect the covalent nature of electrons at $8.0 \mathrm{eV}$ and the metallic nature of electrons at $3.2 \mathrm{eV}$. The existence of induced interface layer depends on $\lambda$ of incident light. Non-local effects in the linear approximation are as sma 11 as $6 \%$ at $\lambda=633 \mathrm{~nm}$ and negligible at $1152 \mathrm{~nm}$.

We would like to thank Prof. G. Wedler for his continuous encouragement. The present work was financially supported by the fund from Japanese Government and the Deutsche Forschungsgemeinschaft.

\section{References}

1. Barteau M.A. and Madix R.J., Surface Sci. 97 (1980) 101.

2. Prince K.C. and Bradshaw A.M., Surface Sci. 126 (1983) 49.

3. Miura Y., Ayame A., Kano H., Miyahara K. and Toyoshima I., "Vacuum" (in Japanese) 25 (1982) 303.

4. Habraken F.H.P.M., Gijzeman O.L.J. and Bootsma G.A., Surface Sci. 96 (1980) 482.

5. Kötz R., Hayden B.E., Schweizer. E. and Bradshaw A.M., Surface Sci.117 (1982) 331.

6. O'Handley R.C. and Burge D.K., Surface Sci. 48 (1975) 214.

7. Merkt U. and Wissmann P., Thin Solid Films 57 (1979) 65, Z.Phys.Chem. (Frankfurt) 115 (1979) 55, Surface Sci. 96 (1980) 529.

8. Wedler G., Chemisorption, Butterworths London 1976, p. 110.

9. Merkt U., App1. Optics 20 (1981) 307.

10. Watanabe $M$. and Wissmann $P$., to be published in surface Sci.

11. Meyer F., Surface Sci. 56 (1976) 37.

12. Melnyk A.R. and Harrison M.J., Phys. Rev. B2 (1970) 835; Forstmann F., Z. Physik B32 (1979) 385.

13. Abeles F. and Lopez-Rios T., Surface Sci. 96 (1980) 32.

14. Abeles F., "Optical Properties of Solids", North Holland Amsterdam 1972, p. 93.

15. Gurzhi R.N., Soviet Phys. JETP 8 (1959) 673; Gurzhi R.N. and Motulevich G.P., Soviet Phys. JETP 24 (1967) 818.

16. Bennett A.J. and Penn D., Phys. Rev. B11 (1975) 3644.

17. Jibetts G.G. and Burkstrand J.M., Phys. Rev. B16 (1977) 1536; Felter T.E. and Weinberg W.H., Surface Sci. 118 (1982) 369. 